\title{
Palladium-Catalyzed Benzylic Arylation
}

Metal-Mediated Synthesis

\section{Key words}

cross-coupling

benzylic arylation

palladium

\section{SYNFACTheh}<smiles>Cc1ccc2cccnc2n1</smiles>

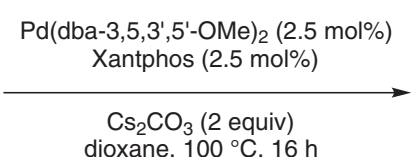
dioxane, $100^{\circ} \mathrm{C}, 16 \mathrm{~h}$

(1)

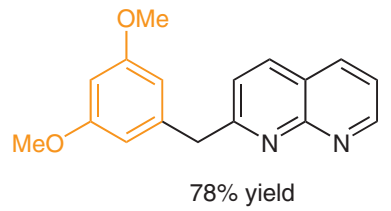<smiles>Clc1cc(Cl)cc(Cc2ccc3cccnc3n2)c1</smiles>

$80 \%$ yield<smiles>CCC(=O)c1ccc(Cc2ccc3cccnc3n2)cc1</smiles>

$60 \%$ yield<smiles>CCOC(=O)c1ccc(Cc2ccccc2C)nc1</smiles>

$75 \%$ yield<smiles>CC(=O)c1ccc(Cc2ccc3cccnc3n2)cc1</smiles>

$63 \%$ yield<smiles>N#Cc1cccc(Cc2ccc3cccnc3n2)c1</smiles>

$70 \%$ yield<smiles>Cc1ccccc1Cc1ccc(C#N)cn1</smiles>

$81 \%$ yield<smiles>FC(F)(F)c1ccc(Cc2ccc3cccnc3n2)cc1</smiles>

$81 \%$ yield<smiles>CCOC(=O)c1cc2ccc(Cc3ccccc3C)nc2nc1C(F)(F)F</smiles>

$76 \%$ yield

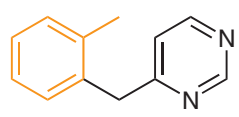

$81 \%$ yield
Significance: The authors report a new direct palladium-catalyzed arylation of benzylic $\mathrm{sp}^{3} \mathrm{C}-\mathrm{H}$ atoms. The mild reaction conditions of this protocol require only low catalyst loadings ( $2.5 \mathrm{~mol} \%)$ and allow a wide functional group tolerance on the benzylic scaffold as well as the aryl moiety. No preactivation of the benzylic position is necessary.
Comment: Aromatics with electron-withdrawing and -donating groups could be introduced in the benzylic position equally well. The palladium source was found to be less important in the reaction; however, the nature of the ligand had a significant effect on the ratio of mono- to bisarylated product. For the same reason equimolar amounts of both coupling partners are used. 